\title{
Continuidad y líneas de fuga en la literatura boliviana contemporánea
}

\author{
Alexander Torres \\ Wells College
}

González Almada, Magdalena. (2017). Relaciones de poder, imaginarios sociales y prácticas identitarias en la narrativa boliviana contemporánea 2000-2010. Córdoba: Universidad Nacional de Córdoba.260 págs.

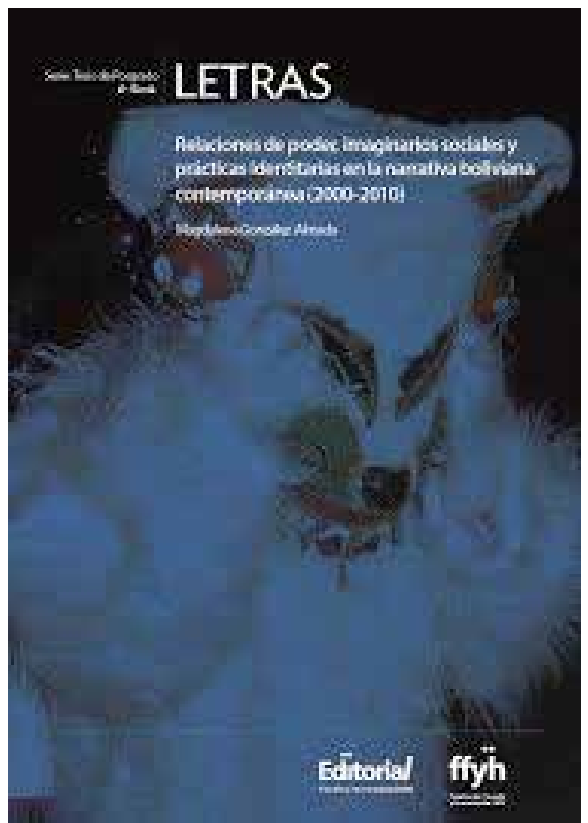

Dada la reciente difusión a nivel internacional de la escritura literaria boliviana, esta publicación de la doctora en letras argentina, Magdalena González Almada, es oportuna y necesaria tanto para entender el panorama en que se encuentra inserta actualmente la literatura boliviana como herramienta teórica que puede facilitar una mayor divulgación de un campo literario que cada vez más se está perfilando más allá de sus fronteras nacionales. En su introducción González Almada (2017) establece que su investigación partirá de "tres ejes conceptuales: relaciones de poder, imaginarios sociales y prácticas identitarias" ( $p$. 2). El corpus determinado por la crítica cordobesa, como indica el título de su obra, abarca el primer decenio del siglo XXI. Este incluye a escritores bolivianos destacados como "Edmundo Paz Soldán, Giovanna Rivero, Juan Pablo Piñeiro, Maximiliano Barrientos, Liliana Colanzi, Sebastián Antezana y Rodrigo Hasbún" (p. 2). Y si bien se concentra en este siglo, el método para acercarse a los objetos de investigación es a través de un diálogo teórico-literario con obras e ideas del siglo anterior. 
Antes de llevarse a cabo un análisis detallado de las obras narrativas, cada capítulo, con excepción de la introducción y la conclusión, presenta consideraciones teóricas cuidadosamente entramadas que guardan relación con los tres ejes conceptuales arriba mencionados. El capítulo uno titulado "La lucha perpetua y multiforme': relaciones de poder en la narrativa boliviana contemporánea" se centra en estas relaciones ligadas a la construcción político-discursiva del Estado-nación boliviano. Y como otras naciones del continente americano, Bolivia ha tenido sus figuras intelectuales que a través de sus obras han pretendido explicar los complejos procesos de colonización, mestizaje y modernidad de su país. En el caso de Alcides Arguedas, González Almada argumenta que "[p]ara Arguedas el indio es el responsable del atraso del país" (p. 67), idea difundida en sus obras más famosas Pueblo enfermo (1909), Raza de bronce (1919) e Historia general de Bolivia (1922) (p. 33). Sin embargo, la forma de visualizar la nación no quedó allí, pues Franz Tamayo con su "Creación de la Pedagogía Nacional (1910) realiza un análisis del mestizo en el que lo idealiza" (p. 43), es decir, que rescata la figura indígena y le da un lugar fundamental en su concepción nacional. Pero hay otros pensadores como René Mercado Zavaleta que, a diferencia de pensadores de rigor como Michel Foucault y Raymond Williams, cuyos aportes teóricos -examinados con inteligencia por González Almada- en lo que respecta a conceptos como discurso y hegemonía, introducen una forma particular de pensar lo boliviano a partir de de teorizaciones provenientes de la tradición europea. Con una mirada más objetiva que sus antecesores, Zavaleta Mercado observa que la hegemonía (político-social) en el caso boliviano, para usar las palabras de Fernando García Yapur, no parte de una "articulación lograda por un sujeto (una clase social, bloque o identidad política) es, más bien, un resultado colectivo, fruto de acumulaciones históricas e intersubjetivas" (como se cita en González Almada, 2017). En otras palabras, la hegemonía sociopolítica en Bolivia no es una formación monolítica, sino una "formación social 'abigarrada'” (p. 30), lo cual supone una presencia siempre constitutiva en lo que atañe a las bases socioculturales indígenas.

De manera inequívoca González Almada demuestra que las relaciones de poder político-social y cultural están determinadas por una dinámica de desplazamiento y reemergencia de las etnias precoloniales. Esto queda reflejado en la tradición literaria boliviana del siglo XX; sin embargo, en el siglo XXI se generan unas desviaciones o elaboraciones notables de esta norma discursiva. Como atinadamente comenta la crítica cordobesa, en El delirio de Turing (2003), de Edmundo Paz Soldán, se nota y se anticipa el distanciamiento de temas nacionales. Aunque la problemática de las relaciones de poder 
en la sociedad boliviana está presente en el trasunto de la Guerra del Agua (ocurrida en 2000), "una rebelión" contra "el avance de las multinacionales en Río Fugitivo, ciudad en la que se mimetiza Cochabamba" (p. 70), hay un descentramiento de lo local a favor de lo global que, como se da a entender en este capítulo, entraña un nuevo conjunto de valores. Con respecto al rol de la mujer en la sociedad boliviana González Almada analiza Las camaleonas (2001) de Giovanna Rivero. Aquí demuestra otro desvío en lo que respecta a "la violencia [que] se ejerce sobre los cuerpos" (p. 76), concretamente el cuerpo femenino. Es decir, describe el alejamiento de los valores tradicionales para la mujer cruceña (de la ciudad oriental de clima cálido Santa Cruz de la Sierra) y, por extensión, la mujer boliviana en general. Otros escritores del siglo XXI que avanzan el impulso de alejarse de la tradición boliviana y de temas como las relaciones de poder sociopolíticas son Sebastián Antezana y Maximiliano Barrientos. Como explica la autora de esta investigación, el "objetivo que se plantean [estos escritores] es el de alejarse de la 'repetición', es decir, se niegan a repetir viejas fórmulas que ya se pusieron en juego en la narrativa boliviana del siglo pasado, por considerarlas gastadas o pasadas de moda" (p. 57). Pero no es solo eso, sino que hay un deseo, ya al parecer generalizado, de formar parte del ámbito literario internacional, pues en Bolivia existe, como asevera Antezana, una "falta de una infraestructura literaria, editorial, periodística y en última instancia cultural que nos permita transformar nuestras letras (como lo hacen otros países) en un producto de exportación, en una marca registrada" (como se cita en González Almada, 2017). Por fin, otra desviación o nueva tendencia que (al mismo tiempo) dialoga con la tradición del siglo pasado es la escritura de Juan Pablo Piñeiro. En su novela Cuando Sara Chura despierte (2003) la figura con raíces indígenas, el cholo, o más concretamente la chola, ha "reaparecido en la narrativa boliviana dándole un nuevo giro a la literatura nacional sin evidenciar las relaciones sociales asimétricas propiciadas por la hegemonía criolla" (p. 83).

El segundo capítulo “'Más reales que la realidad misma': imaginarios sociales en la narrativa boliviana contemporánea" enfatiza este último concepto. Aquí la idea de imaginario social proviene de Cornelius Castoriadis, quien afirma que "las significaciones imaginarias sociales tienen un origen creativo que escapa a una "determinación" social" (p. 94). En otras palabras, la creación discursiva determina la forma en que se imagina a una sociedad. González Almada vincula acertadamente esta práctica con los nuevos modos de narrar que están generando los escritores bolivianos contemporáneos. Al realizar una comparación detallada entre la literatura del siglo XX y la del XXI, la autora se detiene en la figura de la chola en La Chaskañawi (1947), 
de Carlos Medinaceli, y en Cuando Sara Chura despierte, de Piñeiro. Este último escritor reconfigura de forma considerable al personaje de la chola. Pero en la novela de Medinaceli, esta primero aparece "configurada como la causa de [la] degradación" del protagonista mestizo Adolfo (p. 113). Esta degradación aparentemente sería una de las "consecuencias del 'encholamiento'” (p. 110). El temor del "encholamiento" está ausente y se revaloriza la figura de la chola en la novela de Piñeiro. El imaginario social que se crea en Cuando Sara Chura despierte se puede entender a partir de la categoría utilizada por Silvia Rivera Cusicanqui conocida como lo ch'ixi. Este concepto o práctica designa la coexistencia de "múltiples diferencias culturales, que no se funden sino que antagonizan o se complementan" (como se cita en González Almada, 2017). De esta manera Piñeiro se aparta de los discursos del siglo XX boliviano.

A diferencia de este escritor que resignifica o reimagina la etnicidad indígena y la heterogeneidad cultural boliviana, "autores como Liliana Colanzi y Sebastián Antezana parecen 'sentirse como en casa' muy lejos de 'su casa'” (p. 132). González Almada demuestra con libros como Vacaciones permanentes (2010) de Colanzi y La toma del manuscrito (2008) de Antezana un alejamiento de lo local y de lo colectivo hacia lo extraterritorial y lo íntimo. Pero cabe destacar que en Barrientos (como en Rivero y en Colanzi), por ejemplo, en su libro de cuentos Diario (2009), hay un distanciamiento "de cualquier consideración de 'lo nacional", lo cual es sustituido por lo regional, esto es, por el imaginario regional de Santa Cruz de la Sierra (p. 107). Con este gesto se fortalece la posibilidad de crear imaginarios sociales no desde La Paz (la capital administrativa), sino desde otros espacios no hegemonizados por el discurso nacional. Por último, está la idea del "exilio" (p. 155). Este impulso se observa en la escritura de Barrientos, Colanzi y en El lugar del cuerpo (2007) de Rodrigo Hasbún. Con respecto a estos escritores González Almada señala: "Existe un desplazamiento que puede darse o no, pero que es 'deseado' porque al menos se presenta como una expectativa" (p. 155). La autora es cautelosa al dejar en claro que las formas de crear imaginarios sociales desde la escritura boliviana actual no son nada conclusivas en la contemporaneidad y que estas afectan (o están ligadas) a las prácticas identitarias, eje teórico del siguiente capítulo.

El tercer capítulo de esta investigación lleva el título "'Un trabajo de la imaginación': identidad y prácticas identitarias en la narrativa boliviana contemporánea". González Almada identifica tres acercamientos a la producción y las prácticas identitarias dentro de la literatura boliviana, por ejemplo, hay "textos en los cuales aparece la ciudad, generalmente La Paz, con una fuerte impronta, donde las calles y el 
paisaje están referenciados explícitamente, donde la ciudad es nombrada, caracterizada en sus diversos aspectos los denominamos 'literatura marcada"' (p. 163), "textos en los que las temáticas giran alrededor de los viajes, el extrañamiento y la búsqueda de sí que los personajes realizan en lugares lejanos" o "literatura desmarcada" (p. 163) y "una producción literaria "intermedia" (Bhabha, 2002) donde se revela la tensión entre lo local y lo global" (p. 164). El texto que usa como contrapunto para discutir estos temas es Los deshabitados (1959) de Marcelo Quiroga Santa Cruz. La autora destaca cómo la escritura es un medio para inscribir la identidad como sucede con las obras literarias que son fundamentales para la construcción nacional o, dicho de otro modo, para establecer una identidad nacional. No obstante, en la novela de Quiroga Santa Cruz el protagonista, Fernando Durcot, "es un escritor impotente que no puede escribir" (p. 190). Y luego González Almada añade que es "posible pensar que esta impotencia se manifiesta a partir del rechazo a la literatura nacional y a la lengua oficial" (p. 190), pues Durcot hace que los únicos versos que ha escrito sean traducidos al francés porque considera que solo eso dará realce a su verdadero valor.

González Almada asume con creatividad e innovación el riesgo no descabellado de vincular la obra de un autor como Quiroga Santa Cruz con la producción boliviana de este siglo. Al parecer este escritor inaugura la posibilidad de complejizar las dimensionalidades de lo identitario a través de la escritura. Lo que anticipa Los deshabitados se ve ahondado en las obras contemporáneas de la literatura boliviana. Si la escritura para Durcot significa impotencia, para la protagonista de Hasbún, Elena, en El lugar del cuerpo, representa la "única posibilidad de escape, de huida, de trascendencia" (p. 172). La capacidad de escapar, huir o trascender por medio de la literatura se logra mediante novedosas estrategias o acercamientos narrativos. En el apartado "Representaciones de la identidad. Fotografía, sexo y escritura" González Almada analiza cómo las fotos (la forma de narrarlas), la potencia del sexo y la manera de configurar lo que se escribe tipográficamente establecen nuevos modos de construir una identidad a través de la literatura (Barrientos, Antezana, Hasbún, Rivero). Y en el último apartado del capítulo "Lo cotidiano en las prácticas identitarias" la autora demuestra cómo la recomposición del espacio cotidiano sirve para resignificar una identidad. El taypi -noción aymara que "implica una unión" de mundos opuestos (p. 219)- en la obra de Piñeiro, por un lado, reúne "sujetos mestizos, ch'ixis, abigarrados" en el mismo espacio (p. 219). En Las camaleonas de Rivero se ve cómo el espacio doméstico y, por ende, la identidad doméstica, son reconfigurados al ser puestos en crisis. 
Al finalizar la lectura de esta minuciosa investigación, se agradece el acercamiento a un campo cultural cuya heterogeneidad y complejidad son relativamente desconocidas o minimizadas en distintas esferas del pensamiento. No hay solo muchos temas culturales y políticos que recorren el imaginario boliviano, sino que el acercamiento a estos requiere hasta cierto punto la suspensión de los entramados teóricos usados típicamente en otros campos culturales latinoamericanos. De forma impresionante González Almada entreteje el pensamiento europeo "de rigor" con las elaboraciones conceptuales de teóricos como René Zavaleta Mercado y Silvia Rivera Cusicanqui, entre otros. Además, con este trabajo la autora se ha propuesto la importante tarea de aproximarse a su objeto de estudio como una forma de acercarse a la región, a su producción artística y dar cuenta de un fenómeno literario que está en pleno auge. Por último, uno de los cometidos que logra González Almada a lo largo de su obra es el empleo del pensamiento regional, por ejemplo, el argentino y el boliviano, no solo para apuntalar su análisis, sino también para dar fe del acervo conceptual que ya está disponible dentro de la región latinoamericana para comprender sus fenómenos, sus problemas y su promesa. 